\section{DON'T THROW A SPANNER IN THE WORKS}

The National Association of Specialist Dental Accountants and Lawyers (NASDAL) has launched a new campaign to highlight how important it is to have specialist advice. Called 'Don't throw a spanner in the works', it is based around case studies of dentists and their advisors.

Nick Ledingham, NASDAL's chairman, says that the business of dentistry is becoming ever more complex and it has never been more important to have experienced, specialist advisors acting for you.

He provides examples of dental practices helped out by NASDAL members:

- A dentist with an NHS contract was having financial problems and the dentist's non-specialist accountant said: 'Why don't you put your prices up'

- A solicitor helping a dentist buy a practice produced a contract of just two pages (the NASDAL standard contract is 80 essential pages)

- A non-specialist accountant advised an NHS associate to incorporate without warning them of the effect on their NHS pension

- A practice had clawback to pay but the accountant didn't adjust the taxable profit to reflect the lower earnings - so the dentist had to pay an inflated tax bill as well as the clawback in the same year.

To find a specialist dental accountant in your area, visit http://www.nasdal.org.uk.

\title{
TAKING THE HEADACHE OUT OF YOUR PRACTICE SALE
}

If the mere thought of selling your dental practice gives you a headache, consult the experts at Christie + Co. The team can provide all the knowledge and experience you need.

From valuation to sorting out finances and insurance, the process of selling your practice can seem like an intimidating and frightening prospect. Christie+Co offers a bespoke dental brokerage service that suits all needs and takes the stress out of practice sales, and more importantly has experience across all sizes of practice, from small independents to large corporates.

Regulated by the Royal Institution of Chartered Surveyors (RICS), Christie+Co prides itself on its pro- fessional approach, so you can be confident of receiving the highest quality standards of service.

Dental practice sale values have been steadily rising and the market is very buoyant. Contact the team at Christie+Co today to see how their unrivalled commercial experience and proven track record of advising professional practices can help you.

Call Christie+Co today on 02072270700.

http://www.christie.com/en

\section{OPEN UP A NEW RANGE OF OPTIONS TO YOUR PATIENTS}

Take the Inman Aligner training course and you'll open up a range of options to your patients right away. With the ability to straighten anterior teeth in as little as six weeks, the appliance combines speed and simplicity for amazing results.

The hands-on courses run all over the country and there is also an online option. You will become a certified Inman Aligner user immediately, able to handle simpleto-moderate cases with impressive outcomes. All aspects of treatment are covered in training: from case selection and ethical considerations, to space calculation, fitting, adjustment and retention.

The course will teach you everything you need to get started, even if you have little orthodontic experience.
All certified users will be able to access revision courses, marketing material and download the Spacewize+ calculator. Free and full online or phone support is available on an ongoing basis, at any time.

The Inman Aligner course will change the way both you and you patients feel about cosmetic dentistry. Sign up today to realise your full potential.

For queries, go to www.inmanalignertraining.com or telephone 08453665477.

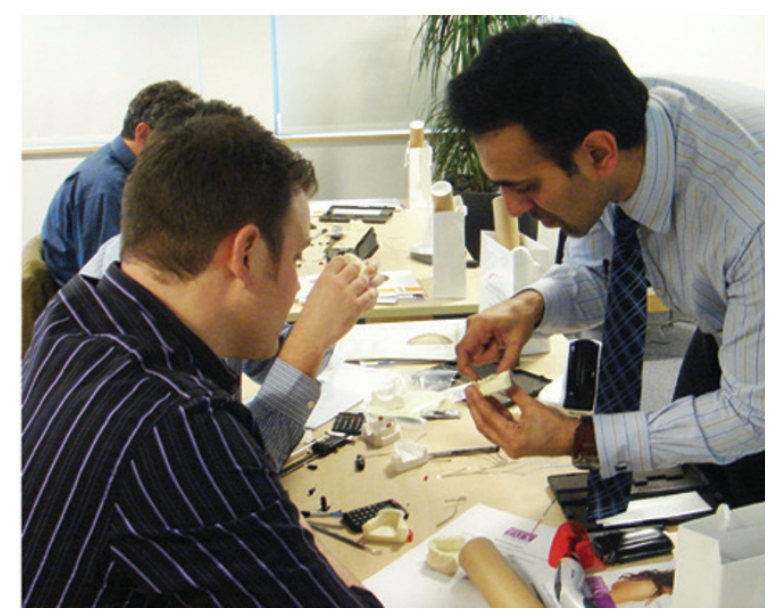

\section{HELP PATIENTS EAT, TALK, LAUGH AND SMILE AGAIN}

More general dental practitioners are discovering that restoring implant cases can be good for their patients and their practice. For the most common treatments, the restorative phase can be completed by the patient's own dentist. Training, support and a mini prosthetics kit are provided free though the DENTSPLY Implants 'R£LAX' programme. Details of local implant partners and 'R£LAX' events can be found on www.dentists4implants.com/relax.
Any GDP can now share in this rapidly growing multi-million pound business, without having to invest a great deal of time and money in learning to place implants. Restoring their own implant cases can improve dentists' reputations and expand their income options, whilst maintain- ing and strengthening long-term patient relationships.

Dental implants can help patients eat, talk, laugh and smile with as much confidence as having their natural teeth.

Contact DENTSPLY Implants UK and Ireland on 08454500586 or by emailing implants.uk@ dentsply.com.

www.dentists4implants.com 